\section{Condições de trabalho, qualidade de vida e disfonia entre docentes}

\author{
Work conditions, quality of life, and voice \\ disorders in teachers
}

\footnotetext{
${ }^{1}$ Faculdade de Medicina, Universidade Federal de Minas Gerais, Belo Horizonte, Brasil.

Correspondência R. Jardim Faculdade de Medicina Universidade Federal de Minas Gerais. Av. Alfredo Balena 190, Belo Horizonte, $M G$ 30130-100, Brasil. jardimre@pop.com.br
}

\begin{abstract}
Voice disorders are common among teachers, with adverse consequences for their work and quality of life. This study focuses on factors associated with voice-related quality of life among female teachers in the municipal school system in Belo Horizonte, Southeast Brazil. A cross-sectional study with 2,133 female teachers was conducted, using the Voice-Related Quality of Life (VRQL) questionnaire, which has two domains: socio-emotional and physical. Teachers were grouped into quartiles based on the distribution of the final score in each domain. Those in the lowest quartile were then compared with all the others for a number of factors, using multiple logistic regression analysis. Less creativity at work and poor relationship with pupils were associated with worse voice-related quality of life in both domains. Mental disorders $\left(G H Q_{12} \geq 4\right)$ were associated with worse voice-related quality of life in the socio-emotional domain, and intraclass noise with worse voice-related quality of life in the physical domain. Improvements in working conditions are key factors for achieving better voice-related quality of life among teachers.
\end{abstract}

Voice Disorders; Faculty; Quality of Life; Occupational Health
Renata Jardim 1

Sandhi Maria Barreto 1

Ada Ávila Assunção 1

\section{Introdução}

Disfonia é qualquer alteração da voz decorrente de um distúrbio funcional e/ou orgânico do trato vocal, podendo expressar-se por vários sintomas: cansaço ou esforço ao falar, rouquidão, pigarro ou tosse persistente, sensação de aperto ou peso na garganta, falhas na voz, falta de ar para falar, afonia, ardência ou queimação na garganta, dentre outros ${ }^{1}$.

O professor disfônico apresenta além de uma série de sinais e sintomas relacionados ao próprio problema de voz, importantes limitações no desenvolvimento de seu trabalho. Como conseqüências da disfonia para o docente, citam-se: (a) redução de atividades ou interações sociais e perda de dias de trabalho 2,3,4,5; (b) dificuldades em sua comunicação e vida social, além de problemas emocionais e psicológicos como conseqüência direta de sua disfonia 4,6; (c) interferências negativas no desempenho do seu trabalho, expressas por dificuldade na aprendizagem dos alunos 7,8; (d) necessidade de "poupar a voz" na sala de aula 9; (e) prejuízos sociais, econômicos, profissionais e pessoais, estimados em cerca de 200 milhões de Reais ao ano, em nosso país 10; (f) dificuldades de relacionamento com os pares, uma vez que alguns colegas de trabalho julgam o professor disfônico como simulador 9; e (g) não aceitação do absenteísmo relacionado à disfonia como um problema de saúde por parte dos gestores públicos da educação e dos 
profissionais de saúde, visto que, as queixas relacionadas à saúde acabam, muitas vezes, sendo interpretadas como simulações ou motivos de "fuga da sala de aula" 11.

Diferentes conceituações de qualidade de vida têm sido usadas, variando de definições gerais às mais específicas. O termo qualidade de vida é abrangente, incluindo fatores relacionados à saúde, como os físicos, funcionais, emocionais e bem-estar mental e, também, os não relacionados, a saber, o trabalho, família, amigos e outros aspectos da vida 12. A qualidade de vida relacionada à saúde envolve vários domínios do cotidiano do indivíduo, sendo os mais comumente estudados o psicológico, o social e o físico 13.

Segundo a Classificação Internacional de Funcionalidade, Incapacidade e Saúde 14, a qualidade de vida lida com o que as pessoas "sentem” sobre sua condição de saúde ou suas conseqüências, sendo, portanto, um construto de "bem-estar subjetivo".

A disfonia é um problema freqüente no trabalho docente 2,3,5,15,16,17 e pouco se conhece sobre o seu impacto na vida do professor no país. O presente trabalho investigou a qualidade de vida relacionada à voz e os fatores associados à pior percepção da mesma, em suas múltiplas dimensões, em docentes da Rede Municipal de Ensino de Belo Horizonte, Minas Gerais, Brasil, usando um questionário internacional padronizado.

\section{Métodos e procedimentos}

Realizou-se um estudo epidemiológico de corte transversal em professores do ensino fundamental da Rede Municipal de Ensino de Belo Horizonte.

Foi feita uma amostra aleatória simples das escolas municipais de Belo Horizonte que estavam em funcionamento em 2004, considerando uma prevalência da disfonia de $50 \%$. Sorteou-se $70 \%$ das escolas municipais nas regionais Noroeste, Leste e Oeste e, as regionais Centro-Sul, Pampulha, Norte e Nordeste foram estudadas integralmente.

Para representatividade da amostra, objetivou-se a inclusão de, no mínimo, $80 \%$ dos professores na ativa em cada escola sorteada, nos turnos de interesse. Nas escolas onde a taxa de resposta foi inferior a $80 \%$, realizou-se outras visitas para recuperação das perdas. As regionais que, mesmo após sucessivos retornos às escolas, não alcançaram a taxa de resposta requerida, não foram incluídas neste estudo.

Participaram do inquérito epidemiológico as professoras do ensino fundamental diurno de 83 escolas, de seis regionais administrativas da cida- de: Centro-Sul, Nordeste, Noroeste, Pampulha, Norte e Leste.

As professoras de educação física não participaram por apresentarem características de ensino bastante diferenciadas das atividades docentes tradicionais. Os professores do sexo masculino não foram incluídos devido ao pequeno número $(\mathrm{n}=137)$ e à diferença de gênero na prevalência da disfonia.

Os dados da literatura e os resultados das entrevistas realizadas junto ao sindicato dos professores e à Gerência de Saúde do Servidor e Perícia Médica de Belo Horizonte, na etapa exploratória, serviram para a elaboração do questionário autoaplicado, sem identificação, que foi construído com questões sócio-demográficas, de saúde vocal, geral e mental, e de ambiente e organização do trabalho.

A presença de transtorno mental foi avaliada pelo General Health Questionnaire-12 (GHQ-12), questionário validado, composto por 12 perguntas. Escore igual ou maior que 4 é considerado positivo, ou seja, presença de transtorno psíquico 18 .

O GHQ, na versão utilizada neste estudo, busca apenas rastrear a presença de transtornos mentais comuns, como depressão e ansiedade.

A qualidade de vida relacionada à voz foi mensurada pelo Protocolo de Qualidade de Vida e Voz (QVV), um questionário internacional padronizado, traduzido e adaptado por Behlau 19 do V-RQOL - Voice-Related Quality of Life ${ }^{20}$. O protocolo é composto por dez questões, abarcando dois domínios: físico e sócio-emocional. As perguntas 1, 2, 3, 6, 7 e 9 referem-se ao funcionamento físico, e as perguntas 4, 5, 8 e 10 ao domínio sócio-emocional. Os objetivos do instrumento são: análise dos aspectos de qualidade de vida relacionados à voz e a quantificação da influência da disfonia no dia-a-dia do indivíduo (Figura 1). Recentemente esse protocolo foi validado para a língua portuguesa e suas medidas psicométricas foram verificadas. A versão brasileira do V-RQOL mostrou-se confiável e válida 21 . Em relação ao questionário adaptado por Behlau ${ }^{19}$, utilizado no presente estudo, os autores fizeram apenas três mudanças na adaptação do texto para a Língua Portuguesa.

A coleta de dados ocorreu entre maio de 2004 e julho de 2005 por meio de visitas realizadas nas escolas selecionadas, no recreio dos professores ou nas reuniões pedagógicas semanais. Quando não foi possível a realização da pesquisa nessas situações, os questionários foram deixados nas escolas e, posteriormente, recolhidos pela equipe da pesquisa. Nesse caso, recomendava-se que os professores selassem os envelopes com os questionários. 
Protocolo de Qualidade de Vida e Voz.

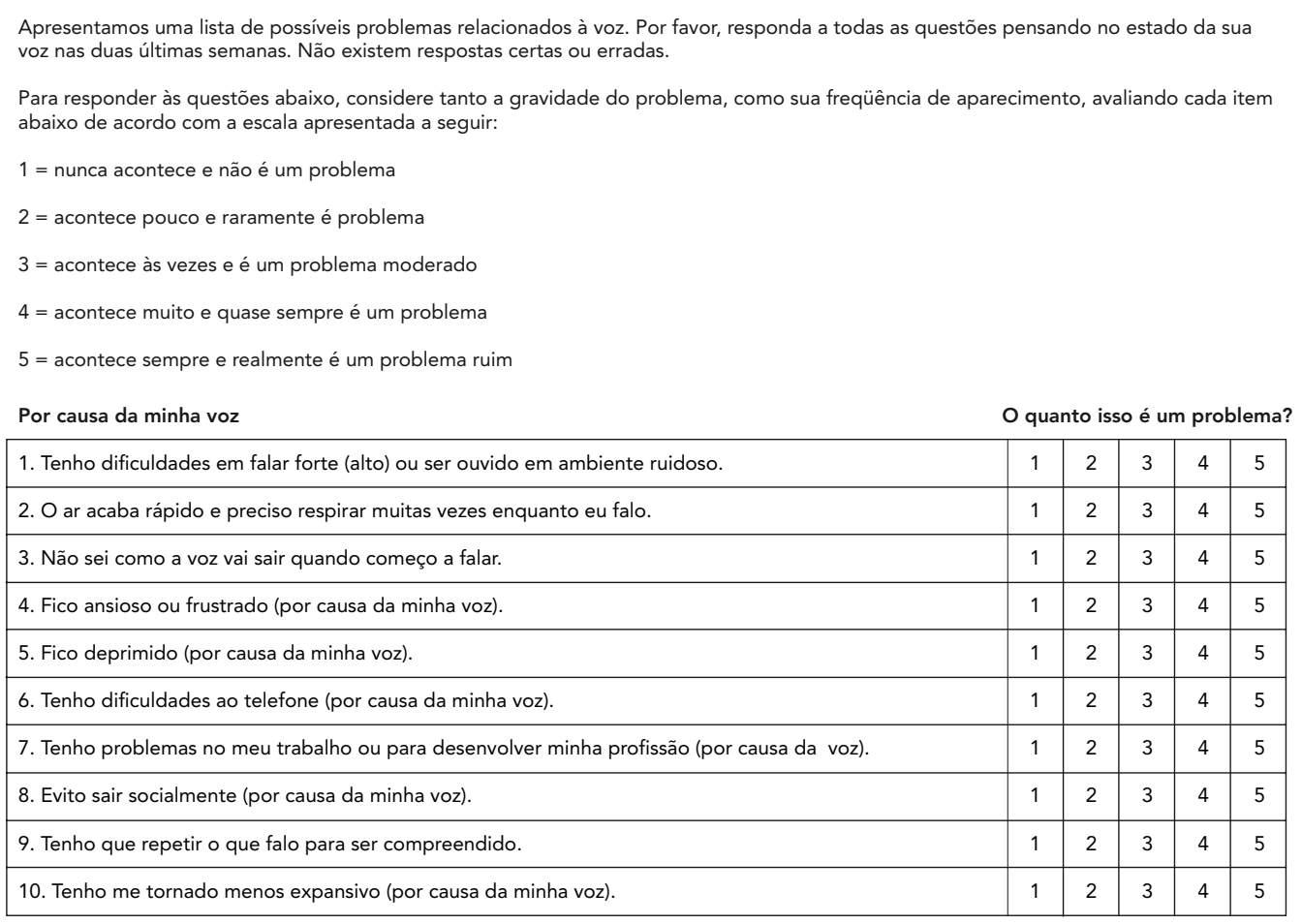

Fonte: desenvolvido por Hogikyan \& Sethuraman 20 e adaptado por Behlau 19.

Antes da aplicação do questionário, os professores foram informados sobre os objetivos da pesquisa, a instituição responsável e o caráter voluntário e sigiloso da participação de cada um.

As variáveis dependentes do estudo foram definidas como os piores escores do QVV total e nos domínios físico e sócio-emocional.

Os escores do QVV são padronizados em uma escala de 0 a 100, sendo que quanto maior o número, melhor a qualidade de vida relacionada à voz. $\mathrm{O}$ menor quartil $\left(\mathrm{P}_{25}\right)$ em cada domínio $\mathrm{e}$ no escore total foi definido como pior qualidade de vida relacionada à voz. O período de referência do QVV são as duas semanas anteriores à entrevista. As fórmulas para calcular os escores do QVV são:

Escore total:

$$
100 \text { - (Escore bruto - 10) } \times 100
$$

Escore do funcionamento físico:

$$
100 \text { - } \underline{\text { (Escore bruto - 6) }} \times 100
$$

24

Escore do domínio sócio-emocional: 100 - (Escore bruto - 4) x 100

16

As variáveis explicativas foram separadas em subconjuntos de variáveis para a construção dos modelos na análise dos dados. As perguntas idade (em anos), número de filhos, tempo de trabalho como professor (em anos), tempo que leciona na escola investigada (em anos), carga horária semanal (em horas) e desempenho de outra função na escola (sim, não e qual) foram abertas. As demais perguntas foram estruturadas variando de duas a sete opções de resposta. As categorias utilizadas na análise ou as opções das respostas encontram-se entre parênteses na frente de cada variável investigada, assim como o detalhamento de algumas perguntas. 
a) Dados sócio-demográficos e de saúde: idade (19-29, 30-39, 40-49, 50-67 anos), estado civil (solteiro, vida conjugal, separado/divorciado, viúvo), renda pessoal e familiar $(\mathrm{R} \$ 240,00-\mathrm{R} \$ 960,00, \mathrm{R} \$$ $960,00-\mathrm{R} \$ 1.600,00, \mathrm{R} \$ 1.600,00-\mathrm{R} \$ 2.400,00$, mais de R\$ 2.400,00), escolaridade (ensino médio, superior, especialização, mestrado, doutorado), número de filhos (0; 1-3; mais de 3), tabagismo ("considerando como fumante quem já fumou pelo menos 100 cigarros, ou 5 maços, na vida, você se classifica como: não fumante, ex-fumante, fumante atual”), uso de medicamento prescrito para depressão, ansiedade ou alterações do sono (não, sim) e transtorno mental (sim, não);

b) Dados sobre o trabalho: tempo de trabalho como docente, carga horária, tempo disponível para preparo das aulas e correção de trabalhos (pequeno, regular, grande), autonomia e criatividade no exercício do trabalho (inexistente/pequena, regular, grande), relacionamentos com superiores, pares, pais e alunos (bom, razoável, ruim) e relato de agressividade por parte de pais de alunos, alunos e pares (nunca, uma vez e mais de uma vez). Utilizou-se uma escala de apreciação variando de um (nenhum ou muito ruim) a 5 (muito ou muito bom) nas questões sobre tempo disponível para preparo das aulas, tempo para correção de trabalhos e avaliação de relacionamentos;

c) Dados sobre a sala de aula: percepção sobre ruído (desprezível ou razoável, elevado ou insuportável), ventilação, iluminação e condições da parede da sala de aula (precária, razoável, satisfatória);

d) Dados referentes às relações entre voz e trabalho: presença de infecções, inflamações ou alergias das vias aéreas superiores (não, sim), relato de cansaço vocal ou piora na qualidade da voz (não, às vezes, diariamente), falta ao trabalho (não, sim) e afastamento do trabalho relacionado à voz (nunca, há mais de 6 meses, nos últimos 6 meses), procura por especialista da área (não, sim), realização de outra atividade com o uso intenso da voz (não, sim), hidratação em sala de aula (não, sim) e quantidade ingerida de água durante o dia (menos de 1 litro, de 1 a 2 litros, mais de 2 litros).

Utilizou-se o programa Epi Info 3.3 (Centers for Disease Control and Prevention, Atlanta, Estados Unidos) para a entrada dos dados. O programa STATA, versão 8.0 (Stata Corp., College Station, Estados Unidos), foi usado para a análise descritiva e para investigação de fatores associados à pior qualidade de vida relacionada à voz. $\mathrm{O}$ presente estudo teve caráter exploratório e, desta forma, procurou identificar hipóteses para pesquisa. Inicialmente, conduziu-se uma análise descritiva dos escores total e dos domínios sócio- emocional e físico do QVV. As diferenças entre as médias e medianas dos escores dos domínios do QVV foram avaliadas por meio do intervalo de confiança de $95 \%$.

A magnitude da associação entre as variáveis dependentes (pior qualidade de vida relacionada à voz total, pior qualidade de vida relacionada à voz no domínio físico e pior qualidade de vida relacionada à voz no componente sócio-emocional) e as variáveis independentes foi estimada pela razão de prevalência e intervalo de confiança de 95\%, obtidos pela regressão de Poisson adaptada para estudos transversais, em todas as três etapas da análise conforme descrito a seguir.

Na primeira etapa, realizou-se a análise univariada considerando-se todas as variáveis independentes de cada subconjunto. Em seguida, todas as variáveis associadas às variáveis dependentes no nível de $\mathrm{p}<0,20$ foram testadas em modelos intermediários, considerando-se apenas as variáveis pertencentes ao mesmo subconjunto.

Sendo a qualidade de vida relacionada à voz uma variável subjetiva, complexa e dinâmica, as variáveis explicativas incluídas no modelo final não foram separadas por categoria temporal, precedente ou conseqüente, visto poderem atuar nos dois sentidos. As variáveis explicativas correlacionadas entre si, como, por exemplo, ruído dentro da sala de aula e ruído na escola, mas fora da sala de aula, foram testadas para selecionar a que apresentasse melhor performance na análise.

Finalmente, foram retidas no modelo final as variáveis que permaneceram estatisticamente associadas às variáveis dependentes no nível de $\mathrm{p}<0,05$, em cada subconjunto.

O projeto desta pesquisa foi aprovado pelo Comitê de Ética em Pesquisa da Universidade Federal de Minas Gerais em 5 de outubro de 2004 (parecer $n^{\circ} .240$ ) e cumpriu os princípios éticos expressos na Declaração de Helsinki.

\section{Resultados}

Participaram desta pesquisa 2.133 professoras. A taxa de resposta média foi de $86 \%$. A média de idade das professoras foi de 42 anos (DP = 8). O uso de medicamento para depressão ou ansiedade e para alterações do sono foi relatado por, respectivamente, $24 \%$ e $11 \%$ das professoras. A prevalência de transtorno mental mensurada pelo GHQ-12 foi de $50 \%$.

Nas últimas duas semanas, $61 \%$ das professoras referiram cansaço para falar e $56 \%$ perceberam piora na qualidade da voz. Aproximadamente $40 \%$ da população estudada sofriam de processo inflamatório, alérgico ou infeccioso nos 
últimos 15 dias. Durante a carreira docente, 30\% das professoras foram afastadas da sala de aula por problemas vocais. O consumo de água durante as aulas foi referido por $71 \%$ das professoras, sendo que $14 \%$ ingeriam mais de 2 litros de água por dia.

Aproximadamente metade das professoras relatou ruído elevado/insuportável na sala de aula (51\%) e na escola, e fora da sala de aula (49\%). Quando pesquisadas sobre a percepção acerca do exercício do trabalho docente, $20 \%$ das professoras relataram ter pouca margem de autonomia, $11 \%$ pequena possibilidade de ser criativa, $36 \%$ pouco tempo para o preparo das aulas e $44 \%$ pouco tempo para a correção de trabalhos.

As professoras presenciaram episódios de agressão no último ano nas escolas envolvendo alunos (71\%), pais de alunos (53\%), funcionários ou professores (16\%) e pessoas externas à escola (49\%). A grande maioria das professoras considera ter bons relacionamentos no trabalho com alunos (87\%), com colegas (86\%), com superiores (80\%) e com pais de alunos $(74 \%)$.

Os valores médios encontrados para os escores do QVV e seus respectivos intervalos de confiança foram: 84,2 $(83,4-84,9)$ no escore total, $79,4(78,6-80,2)$ no físico e 90,6 $(89,9-91,3)$ no escore sócio-emocional. As diferenças entre as médias e medianas nos domínios sócio-emocional e físico do QVV foram estatisticamente significantes. O percentil 25 do escore total foi igual a 78, do escore físico igual a 67 e do sócioemocional igual a 88 .

As associações entre a pior qualidade de vida relacionada à voz e as características sócio-demográficas, de saúde e de carga de trabalho encontram-se na Tabela 1. As variáveis que estiveram associadas às variáveis dependentes foram: uso de medicamentos para depressão e ansiedade e para alterações do sono, presença de transtorno mental e presença de processo alérgico ou inflamatório das vias aéreas superiores.

Associações entre a pior qualidade de vida relacionada à voz às características sócio-demográficas, de saúde e carga de trabalho das professoras da rede municipal de ensino de Belo Horizonte, Minas Gerais, Brasil, 2004-2005.

\begin{tabular}{|c|c|c|c|c|}
\hline \multicolumn{5}{|c|}{ Pior qualidade de vida relacionada à voz total * } \\
\hline Características sócio-demográficas de saúde e carga de trabalho & $\mathbf{n}$ & $\%$ & RP & IC95\% \\
\hline \multicolumn{5}{|l|}{ Idade (anos) } \\
\hline $19-29$ & 115 & 5,69 & 1,00 & \\
\hline $30-39$ & 650 & 32,16 & 0,97 & $0,94-1,00$ \\
\hline $40-49$ & 862 & 42,65 & 0,95 & $0,92-0,99$ \\
\hline $50-67$ & 394 & 19,50 & 0,99 & $0,95-1,03$ \\
\hline \multicolumn{5}{|l|}{ Escolaridade } \\
\hline Pós-graduação & 1,031 & 50,42 & 1,00 & \\
\hline Superior & 889 & 43,47 & 1,01 & $0,99-1,03$ \\
\hline Médio & 125 & 6,11 & 1,03 & $1,00-1,07$ \\
\hline \multicolumn{5}{|l|}{ Estado civil } \\
\hline Sem vida conjugal & 869 & 42,33 & 1,00 & \\
\hline Com vida conjugal & 1.184 & 57,67 & 1,00 & $0,99-1,03$ \\
\hline \multicolumn{5}{|l|}{ Filhos } \\
\hline 0 & 575 & 29,40 & 1,00 & \\
\hline $1-2$ & 1.038 & 53,07 & 0,99 & $0,97-1,00$ \\
\hline $3-8$ & 343 & 17,54 & 1,00 & $0,98-1,04$ \\
\hline \multicolumn{5}{|l|}{ Renda total pessoal (em Reais) } \\
\hline$>2.400,00$ & 322 & 15,77 & 1,00 & \\
\hline $1.600,00-2.400,00$ & 810 & 39,67 & 0,99 & $0,96-1,02$ \\
\hline $240,00-1.600,00$ & 910 & 44,56 & 0,99 & $0,96-1,01$ \\
\hline \multicolumn{5}{|l|}{ Renda total familiar (em Reais) } \\
\hline$>2.400,00$ & 1.024 & 50,34 & 1,00 & \\
\hline $1.600,00-2.400,00$ & 682 & 33,53 & 1,01 & $0,99-1,03$ \\
\hline $240,00-1.600,00$ & 328 & 16,13 & 1,00 & $0,97-1,03$ \\
\hline
\end{tabular}

(continua) 
Pior qualidade de vida relacionada à voz total *

Características sócio-demográficas de saúde e carga de trabalho

$\%$
$15-40$

Carga horária semanal (horas)

$<22,30$

22,30

$22,30-80,00$

Número de ciclos em que leciona

$$
1
$$

2

Número de turnos em que leciona

1

2

3

Desempenha outra função na escola Não

Sim

Trabalha em outra escola

Não

Sim

Outra atividade remunerada

Não

Sim

Outra atividade com uso freqüente da voz

Não

Sim
773

393

449

443

1.002

1.156

771

712

1.277

47

1.815

230

1.206

837

1.821

214

1.710

335
57,98

42,02

22,06

30,82

47,12

73,05

26,95

76,01

23,99

89,27

10,73

50,29

49,71

6,22

8,21

19,74

22,21

43,62

41,14

15,65

22,30

20,92

RP

IC95\%

1,00

0,90

1,00

0,99

0,98

0,97-1,02

0,95-1,00

1,00

1,01

1,00

0,93

1,00

0,9

$0,87-0,94$

1,00

0,91

$0,89-0,92$

1,00

0,99

0,97

0,97

0,97

1,00

0,96

1,5

1,01

1,00

0,99

0,98

0,97-1,02

23,39

52,90

59,99

40,01

1,00

1,00

$0,98-1,02$

34,97

62,72

2,31

1,00

0,99

1,02

0,97-1,00

0,96-1,08

88,75

11,25

1,00

0,99

$0,96-1,02$

59,03

40,97

1,00

1,00

0,98-1,02

89,48

10,52

1,00

0,88

$0,66-1,16$

83,62

1,00

1,00

$0,97-1,02$

(continua) 
Pior qualidade de vida relacionada à voz física **

Características sócio-demográficas de saúde e carga de trabalho

n

$\%$

RP

IC95\%

Idade (anos)

19-29

30-39

40-49

50-67

Escolaridade

Pós-graduação

Superior

Médio

Estado civil

Sem vida conjugal

Com vida conjugal

Filhos

0

$1-2$

3-8

Renda total pessoal (em Reais)

$$
>2.400,00
$$

$1.600,00-2.400,00$

240,00-1.600,00

Renda total familiar (em Reais)

$$
>2.400,00
$$

$1.600,00-2.400,00$

$240,00-1.600,00$

Processo inflamatório/alérgico nas vias áreas superiores

Não

Sim

Atividade física regular ( vezes por semana)

3 ou mais

$1-2$

Nenhuma

Tabagismo

Não

Sim

Medicamentos para depressão/ansiedade

Não

Sim

Medicamentos para alterações do sono

Não

Sim

Transtorno mental

$\mathrm{GHO}$ -

$\mathrm{GHO}+$

Tempo de docência (anos)

$0-4$

5-9

10-14

15-19

20-53

Tempo de docência na escola (anos)

$0-4$

5-9

10-14

15-40
117

656

873

404

1.045

902

127

886

1.196

584

1.050

351

329

822

920

1.035

696

332

1.202

876

453

641

966

1.489

550

1.586

502

1.861

227

952

948

118

154

373

419

827

782

296

427

401
5,71

32,00

42,59

19,71

50,39

43,49

6,12

42,56

57,44

29,42

52,90

17,68

15,89

39,69

44,42

50,17

33,74

16,09

57,84

42,16

21,99

31,12

46,89

73,03

26,97

75,96

24,04

89,13

10,87

50,11

49,89

6,24

8,14

19,73

22,16

43,73

41,03

15,53

22,40

21,04
1,00

1,02

1,19

0,94

$0,71-1,48$

0,83-1,69

$0,63-1,38$

1,00

0,9

0,84

0,77-1,05

0,59-1,20

1,00

1,06

$0,91-1,24$

1,00

1,07

1,06

0,84-1,35

$0,77-1,44$

1,00

1,16

1,20

0,91-1,48

0,94-1,52

1,00

0,84

1,04

0,70-1,00

0,84-1,28

1,00

2,14

$1,83-2,51$

1,00

1,00

1,12

0,80-1,25

$0,92-1,38$

1,00

1,03

$0,86-1,22$

1,00

1,78

$1,53-2,07$

1,00

1,81

$1,51-2,18$

1,00

2,22

$1,86-2,65$

1,00

1,07

0,66-1,72

0,86-1,94

0,81-1,82

0,87-1,89

1,21

1,28

$1,32-2,04$

1,14-1,73

$0,82-1,33$

(continua) 
Tabela 1 (continuação)

Pior qualidade de vida relacionada à voz física **

Características sócio-demográficas de saúde e carga de trabalho $\quad$ n $\%$

RP

IC95\%

Carga horária semanal (horas)

$$
\begin{aligned}
& <22,30 \\
& 22,30 \\
& 22,30-80,00
\end{aligned}
$$

Número de ciclos em que leciona

$$
1
$$$$
2
$$

Número de turnos em que leciona

1
2
3

Desempenha outra função na escola

Não

Sim

Trabalha em outra escola

Não

Sim

Outra atividade remunerada

Não

Sim

Outra atividade com uso freqüente da voz

Não

Sim

452

450

1.017

$\%$

23,55

23,45

53,00

1168

786

718

1.298

49

1.839

235

1.217

854

1.848

216

1.734

340

59,77

40,23

34,77

62,86

2,37

88,67

11,33

58,76

41,24

89,53

10,47

83,61

16,39
1,00

1,16

1,25

1,00

1,05

1,00

1,07

1,08

1,00

1,06

1,00

0,99

1,00

0,85

1,00

1,00
$0,90-1,24$

$0,91-1,26$

$0,65-1,80$

$0,84-1,35$

$0,84-1,16$

$0,64-1,12$

$0,81-1,23$

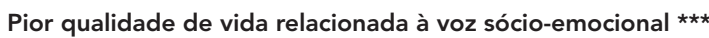

Características sócio-demográficas de saúde e carga de trabalho n

\begin{tabular}{|c|c|c|c|c|}
\hline \multicolumn{5}{|l|}{ Idade (anos) } \\
\hline $19-29$ & 117 & 5,71 & 1,00 & \\
\hline $30-39$ & 656 & 32,03 & 1,38 & $0,95-1,99$ \\
\hline $40-49$ & 876 & 42,77 & 1,61 & $1,12-2,30$ \\
\hline $50-67$ & 399 & 19,48 & 1,18 & $0,80-1,74$ \\
\hline \multicolumn{5}{|l|}{ Escolaridade } \\
\hline Pós-graduação & 1.045 & 50,41 & 1,00 & \\
\hline Superior & 903 & 43,56 & 0,94 & $0,82-1,08$ \\
\hline Médio & 125 & 6,03 & 0,77 & $0,55-1,06$ \\
\hline \multicolumn{5}{|l|}{ Estado civil } \\
\hline Sem vida conjugal & 881 & 42,34 & 1,00 & \\
\hline Com vida conjugal & 1.200 & 57,66 & 0,92 & $0,80-1,05$ \\
\hline \multicolumn{5}{|l|}{ Filhos } \\
\hline 0 & 580 & 29,26 & 1,00 & \\
\hline $1-2$ & 1.054 & 53,18 & 1,17 & $0,99-1,37$ \\
\hline $3-8$ & 348 & 17,56 & 0,99 & $0,80-1,24$ \\
\hline \multicolumn{5}{|c|}{ Renda total pessoal (em Reais) } \\
\hline$>2.400,00$ & 324 & 15,65 & 1,00 & \\
\hline $1.600,00-2.400,00$ & 816 & 39,42 & 1,06 & $0,87-1,31$ \\
\hline $240,00-1.600,00$ & 930 & 44,93 & 1,10 & $0,90-1,35$ \\
\hline \multicolumn{5}{|c|}{ Renda total familiar (em Reais) } \\
\hline$>2.400,00$ & 1.032 & 50,05 & 1,00 & \\
\hline $1.600,00-2.400,00$ & 696 & 33,75 & 0,96 & $0,83-1,11$ \\
\hline $240,00-1.600,00$ & 334 & 16,20 & 1,01 & $0,84-1,22$ \\
\hline \multicolumn{5}{|c|}{ Processo inflamatório/alérgico nas vias áreas superiores } \\
\hline Não & 1.200 & 57,78 & 1,00 & \\
\hline Sim & 77 & 42,22 & 1,79 & $1,57-2,04$ \\
\hline
\end{tabular}

$\%$

RP

IC95\%

(continua) 
Pior qualidade de vida relacionada à voz sócio-emocional ***

Características sócio-demográficas de saúde e carga de trabalho

n

$\%$

RP

IC95\%

Atividade física regular ( vezes por semana)

3 ou mais

$1-2$

Nenhuma

Tabagismo

Não

Sim

Medicamentos para depressão/ansiedade

Não

Sim

Medicamentos para alterações do sono

Não

Sim

Transtorno mental

$\mathrm{GHO}$ -

$\mathrm{GHQ}+$

Tempo de docência (anos)

$0-4$

$5-9$

10-14

15-19

20-53

Tempo de docência na escola (anos)

$0-4$

5-9

10-14

15-40

Carga horária semanal (horas)

$<22,30$

22,30

22,30-80,00

Número de ciclos em que leciona

1

2

Número de turnos em que leciona

1

2

3

Desempenha outra função na escola

Não

Sim

Trabalha em outra escola

Não

Sim

Outra atividade remunerada

Não

Sim

Outra atividade com uso freqüente da voz

Não

Sim
453

638

968

1.491

591

1.585

502

1.865

222

951

946

117

156

70

423

25

787

296

423

398

454

448

1.017

1.175

780

717

1.300

47

1.843

230

1.221

850

1.845

217

1.730

342
22,00

99,00

47,01

73,12

26,88

75,95

24,05

36,00

10,64

50,13

49,87

6,19

8,25

19,57

22,36

43,63

41,33

15,55

22,22

20,90

23,66

23,35

53,00

60,10

39,90

34,74

62,98

2,28

88,90

11,10

58,96

41,04

89,48

10,52

83,49

16,51
1,00

1,18

1,31

0,96-1,44

$1,09-1,57$

0,80-1,09

0,93

1,00

1,47

$1,29-1,68$

1,00

1,59

1,35-1,87

1,00

1,90

$1,64-2,21$

1,00

0,77

0,89

0,93

0,97

$0,53-1,12$

0,66-1,21

0,69-1,26

$0,74-1,29$

1,09-1,58

1,04-1,47

$0,79-1,18$

1,23

0,97

1,00

1,05

1,13

0,86-1,29

0,95-1,34

1,00

1,01

$0,88-1,16$

1,00

1,06

0,95

0,92-1,22

$0,59-1,54$

1,00

0,90

$0,72-1,12$

1,00

1,10

$0,97-1,26$

1,00

0,86

0,68-1,09

1,00

1,08

$0,91-1,28$

RP: razão de prevalência; IC95\%: intervalo de confiança a 95\%; GHQ: General Health Questionnaire.

Nota: o total da soma dos participantes apresenta pequenas variações devido a perdas.

* Escore total correspondente às dez perguntas do Protocolo de Qualidade de Vida e Voz;

** Escore do domínio físico correspondente às perguntas 1, 2, 3, 6, 7 e 9 do Protocolo de Qualidade de Vida e Voz;

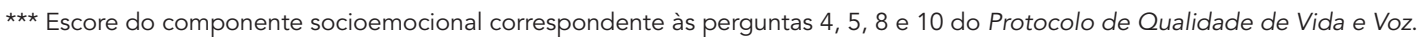


Na Tabela 2 encontram-se as associações entre as variáveis dependentes e a experiência de violência na escola, relacionamentos, relações entre a voz e o trabalho, ambiente físico da escola e a percepção sobre o trabalho. Todas as associações foram estatisticamente associadas com uma pior qualidade de vida relacionada à voz, salvo quantidade de água ingerida durante o dia no domínio físico e agressão por funcionários ou professores nos domínios físico e sócio-emocional.
A Tabela 3 apresenta as associações encontradas no modelo final. Houve uma associação positiva entre pior qualidade de vida relacionada à voz e todas as variáveis, exceto consumo de água, que apresentou uma associação protetora em relação à pior qualidade de vida relacionada à voz no domínio físico. Transtorno mental e margem de autonomia no trabalho foram associados à pior qualidade de vida relacionada à voz apenas no componente sócio-emocional. Já o fator ruído na sala de aula esteve associado apenas à pior qualidade de vida relacionada à voz no domínio físico.

Tabela 2

Associações entre a pior qualidade de vida relacionada à voz e aspectos das relações entre voz e trabalho, ambiente físico da escola, violência, relacionamentos e percepção sobre o trabalho pelas professoras da rede municipal de ensino de Belo Horizonte, Minas Gerais, Brasil, 2004-2005.

Pior qualidade de vida relacionada à voz total *

Aspectos das relações entre voz e trabalho, ambiente físico da escola,

violência, relacionamentos e percepção sobre o trabalho

$\%$

RP

IC95\%

\begin{tabular}{|c|c|c|c|c|}
\hline \multicolumn{5}{|l|}{ Relato de cansaço para falar } \\
\hline Não & 818 & 39,82 & 1,00 & \\
\hline Às vezes & 994 & 48,39 & 5,52 & $4,04-7,54$ \\
\hline Diariamente & 242 & 11,78 & 14,00 & $10,32-19,00$ \\
\hline \multicolumn{5}{|c|}{ Percepção de piora na qualidade da voz } \\
\hline Não & 916 & 44,57 & 1,00 & \\
\hline Às vezes & 903 & 43,94 & 4,85 & $3,69-6,37$ \\
\hline Diariamente & 236 & 11,48 & 12,05 & $9,25-15,72$ \\
\hline \multicolumn{5}{|c|}{ Procurou médico/fonoaudiólogo por causa da voz } \\
\hline Não & 1.914 & 93,23 & 1,00 & \\
\hline Sim & 139 & 6,77 & 2,51 & $2,11-2,98$ \\
\hline \multicolumn{5}{|c|}{ Afastamento da carreira por causa da voz } \\
\hline Nunca & 1441 & 70,29 & 1,00 & \\
\hline Há mais de 6 meses & 511 & 24,93 & 1,92 & $1,65-2,24$ \\
\hline \multicolumn{5}{|c|}{ Consumo de água durante as aulas } \\
\hline Sim & 1.478 & 70,96 & 1,00 & \\
\hline Não & 605 & 29,04 & 0,79 & $0,66-0,94$ \\
\hline \multicolumn{5}{|c|}{ Quantidade de água ingerida durante o dia (litros) } \\
\hline$>2$ & 284 & 13,84 & 1 & \\
\hline $1-2$ & 1.096 & 53,41 & 0,76 & $0,62-0,94$ \\
\hline$<1$ & 672 & 32,75 & 0,81 & $0,65-1,01$ \\
\hline \multicolumn{5}{|l|}{ Ruído gerado na sala de aula } \\
\hline Desprezível a razoável & 1.020 & 49,73 & 1,00 & \\
\hline Elevado a insuportável & 1.031 & 50,27 & 2,04 & $1,72-2,41$ \\
\hline \multicolumn{5}{|l|}{ Ruído gerado na escola } \\
\hline Desprezível a razoável & 1.054 & 51,44 & 1,00 & \\
\hline Elevado a insuportável & 995 & 48,56 & 1,61 & $1,38-1,88$ \\
\hline \multicolumn{5}{|l|}{ Ruído gerado fora da escola } \\
\hline Desprezível a razoável & 1.664 & 81,21 & 1,00 & \\
\hline Elevado a insuportável & 385 & 18,79 & 1,49 & $1,26-1,76$ \\
\hline
\end{tabular}

(continua) 
Pior qualidade de vida relacionada à voz total *

Aspectos das relações entre voz e trabalho, ambiente físico da escola

violência, relacionamentos e percepção sobre o trabalho

n

$\%$ RP

IC95\%

Ventilação na sala de aula

Satisfatória

Razoável

902

Precária

500

43,98

1,68

1,68
1,87

$1,37-2,0$

Iluminação na sala de aula

Satisfatória

Razoável

810

980

Precária

264

24,38

1,00

39,44

47,71

1,62

2,00

$1,59-2,51$

Condições das paredes da sala de aula

Satisfatória

Razoável

1.037

850

12,85

1,00

0,96

0,73

0,74-1,26

Precária

164

41,44

8,00

$0,56-0,95$

Margem de autonomia

Grande

552

27,02

1,00

$1,36-2,05$

Pequena/Razoável

1.491

72,98

1,67

Possibilidade de ser criativo

Grande

972

Pequena/Razoável

47,44

52,56

1,00

1,57

$1,33-1,84$

Tempo para preparação de aulas

Grande

18,75

45,63

Razoável

Pequeno

35,62

1,21

1,55

$0,95-1,54$

722

Tempo para correção de trabalhos

Grande

15,40

1,00

Razoável

311

41,14

1,19

1,45

$0,92-1,56$

878

43,47

$1,13-1,87$

Agressão por alunos (vezes)

Nunca

28,56

1,00

188

9,40

62,03

1,33

$0,98-1,80$

$>1$

1.240

46,76

$1,20-1,78$

Agressão por pais de alunos (vezes)

Nunca

931

12,96

$>1$

40,28

1,5

$1,18-1,90$

802

Agressão por funcionários/professores (vezes)

Nunca

1.697

$>1$

84,30

1,00

1,20

1,32

$0,88-1,62$

9,84

$1,12-1,54$

Agressão por pessoas externas à escola (vezes)

Nunca

1.009

$>1$

50,96

1,00

0,92

1,31

$0,69-1,24$

762

38,48

$1,23-1,86$

Relacionamento com superiores

Bom

1.627

79,91

1,00

276

Razoáve

Ruim

133

13,56

6,53

1,52

1,43

$1,26-1,84$

Relacionamento com colegas

Bom

1.753

Razoável

Ruim

229

57

85,97

1,00

11,23

2,80

1,27

$1,02-1,58$

Relacionamento com alunos

Bom

1.781

87,39

Razoável

217

10,65

1,28

$0,85-1,92$

Ruim

40

1,96

1,00

1,62

1,33-1,97

1,67

$1,11-2,51$

(continua) 
Pior qualidade de vida relacionada à voz total *

Aspectos das relações entre voz e trabalho, ambiente físico da escola,

violência, relacionamentos e percepção sobre o trabalho

n $\%$

RP

IC95\%

Relacionamento com pais de alunos

$\begin{array}{lccr}\text { Bom } & 1.510 & 74,06 & 1,00 \\ \text { Razoável } & 329 & 16,14 & 1,23 \\ \text { Ruim } & 200 & 9,81 & 1,00-1,50\end{array}$

Pior qualidade de vida relacionada à voz física **

Aspectos das relações entre voz e trabalho, ambiente físico da escola,

violência, relacionamentos e percepção sobre o trabalh

n $\%$

RP

IC95\%

Relato de cansaço para falar

Não

823

Às vezes

Diariamente

Percepção de piora na qualidade da voz

Não

Às vezes

44,19

Procurou médico/fonoaudiólogo por causa da voz

Afastamento da carreira por causa da voz

\section{Nunca}

Há mais de 6 meses

Nos últimos 6 meses

Consumo de água durante as aulas

$$
\text { Sim }
$$

Não

Quantidade de água ingerida durante o dia (litros)

$$
\begin{aligned}
& >2 \\
& 1-2 \\
& <1
\end{aligned}
$$

Desprezível a razoável

Elevado a insuportável

Ruído gerado na escola

Desprezível a razoável

Elevado a insuportável

Ruído gerado fora da escola

Ventilação na sala de aula

\section{Satisfatória}

Razoável

Precária

31,54

Iluminação na sala de aula

Satisfatória

39,41

1,00

821

47,58

13,01

Condições das paredes da sala de aula

\section{Satisfatória}

50,77

(continua) 
Pior qualidade de vida relacionada à voz física **

Aspectos das relações entre voz e trabalho, ambiente físico da escola

violência, relacionamentos e percepção sobre o trabalho

$\%$

RP

IC95\%

Possibilidade de ser criativo

Grande

987

Pequena/Razoável

1.091

47,50

1,00

Tempo para preparação de aulas

Grande

385

Razoável

933

Pequeno

736

Tempo para correção de trabalhos

Grande

Razoável

313

838

Pequeno

897

Agressão por alunos (vezes)

Nunca

577

1

$>1$

193

1.258

52,50

1,43

$1,22-1,68$

18,74

1,00

1,04

45,42

35,83

1,43

$0,82-1,31$

$1,14-1,80$

Agressão por pais de alunos (vezes)

Nunca

946

15,28

1,00

1,15

40,92

1,47

0,89-1,50

43,80

$1,14-1,89$

1

$>1$

264

809

28,45

1,00

1,13

1,42

$0,82-1,56$

62,03

1,17-1,73

Agressão por funcionários/professores (vezes)

Nunca 1.725

$1 \quad 118$

$>1$

118
199

Agressão por pessoas externas à escola (vezes)

Nunca

1

$>1$

1.025

211

773

Relacionamento com superiores

Bom

Razoável

1.649

280

Ruim

135

Relacionamento com colegas

Bom

Razoável

Ruim

1.775

233

59

46,85

1,00

1,29

1,59

$1,00-1,66$

40,07

$1,34-1,88$

84,48

1,00

0,97

1,22

$0,69-1,37$

9,75

$0,96-1,54$

$51,02 \quad 1,00$

$10,50 \quad 1,03$

$0,78-1,36$

38,48

$1,13-1,57$

1,33

79,89

1,00

1,60

1,33-1,93

13,57

1,52

$1,17-1,97$

Relacionamento com alunos

Bom

1.802

221

Razoável

Ruim

42

85,98

1,00

1,36

1,34

$1,10-1,67$

11,27

$0,90-1,99$

Relacionamento com pais de alunos

Bom

1.528

335

204

87,26

1,00

1,60

$1,31-1,95$

10,70

$1,26-2,67$

Razoável

73,92

16,21

1,00

Ruim

9,87

1,27

$1,04-1,55$

$1,42-2,12$

Pior qualidade de vida relacionada à voz sócio-emocional ***

Aspectos das relações entre voz e trabalho, ambiente físico da escola,

violência, relacionamentos e percepção sobre o trabalho

n

$\%$

RP

IC95\%

Relato de cansaço para falar

$\begin{array}{lccr}\text { Não } & 824 & 39,58 & 1,00 \\ \text { Às vezes } & 1.014 & 48,70 & 3,96 \\ \text { Diariamente } & 244 & 11,72 & 3,15-4,97\end{array}$

(continua) 
Tabela 2 (continuação)

Pior qualidade de vida relacionada à voz sócio-emocional ***

Aspectos das relações entre voz e trabalho, ambiente físico da escola,

violência, relacionamentos e percepção sobre o trabalho

$\%$

Percepção de piora na qualidade da voz

Não

Às vezes

Diariamente

Procurou médico/fonoaudiólogo por causa da voz

Não

Sim

Afastamento da carreira por causa da voz

\section{Nunca}

Há mais de 6 meses

Nos últimos 6 meses

Consumo de água durante as aulas

$$
\text { Sim }
$$

Não

Quantidade de água ingerida durante o dia (litros)

$$
\begin{aligned}
& >2 \\
& 1-2
\end{aligned}
$$$$
<1
$$

Ruído gerado na sala de aula

Desprezível a razoável

Elevado a insuportável

Ruído gerado na escola

Desprezível a razoável

Elevado a insuportável

Ruído gerado fora da escola

Desprezível a razoável

Elevado a insuportável

Ventilação na sala de aula

Satisfatória

Razoável

Precária

lluminação na sala de aula

Satisfatória

Razoável

Precária

Condições das paredes da sala de aula

Satisfatória

Razoável

Precária

Margem de autonomia

Grande

Pequena/Razoável

Possibilidade de ser criativo

Grande

Pequena/Razoável

Tempo para preparação de aulas

Grande

Razoável

Pequeno

Tempo para correção de trabalhos

Grande

Razoável

Pequeno n

925

920

238

1.938

143

1461

588

29

1.467

601

285

1.108

687

1.032

1.047

1.068

1.009

1.688

389

655

914

510

823

991

268

1.054

860

165

556

1.515

991

1.086

384

939

732

312

846

890
44,41

44,17

11,43

93,13

6,87

70,31

28,30

1,40

70,94

29,06

13,70

53,27

33,03

49,64

50,36

51,42

48,58

81,27

18,73

31,51

43,96

24,53

39,53

47,60

12,87

50,70

41,37

7,94

26,85

73,15

47,71

52,29

18,69

45,69

35,62

15,23

41,31

43,46
RP

IC95\%

1,00

3,80

7,12

$3,09-4,67$

$5,80-8,74$

1,00

2,00

$1,71-2,35$

1,00

1,69

2,64

1,48-1,92

$2,00-3,50$

1,00

0,80

0,69-0,94

1,00

0,79

0,81

$0,66-0,95$

$0,67-0,99$

1,00

1,62

$1,41-1,85$

1,00

1,37

$1,20-1,56$

1,00

1,36

$1,18-1,58$

1,00

1,58

1,67

1,33-1,88

$1,38-2,02$

1,00

1,54

1,68

1,32-1,79

$1,37-2,05$

1,00

1,27

1,32

$1,11-1,46$

$1,05-1,67$

1,43-2,05

1,00

1,71

1,00

1,59

$1,38-1,82$

1,00

1,23

1,49

1,00-1,51

$1,21-1,83$

1,00

1,12

1,36

$0,90-1,40$

$1,10-1,69$

(continua) 
Pior qualidade de vida relacionada à voz sócio-emocional **

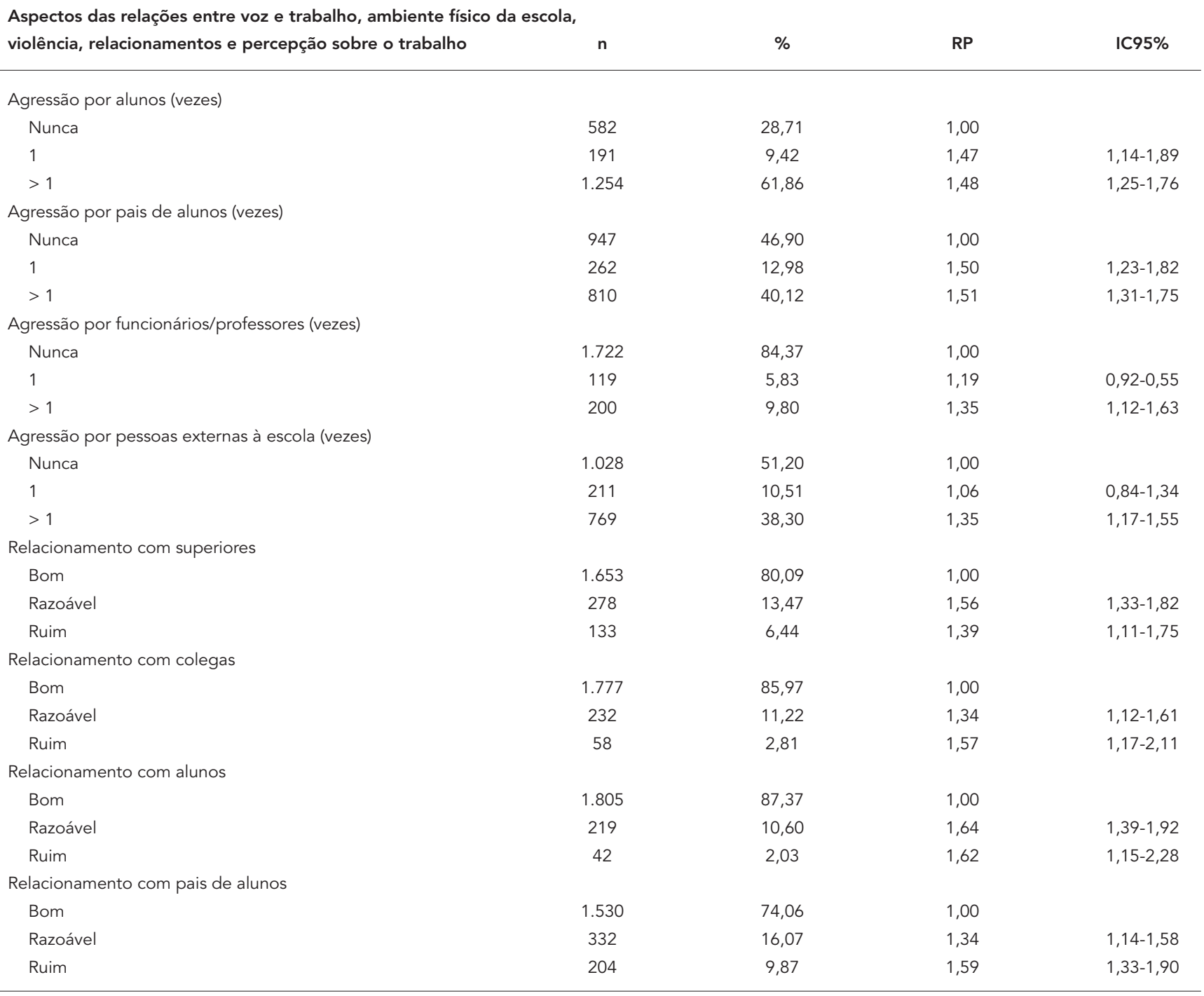

RP: razão de prevalência; IC95\%: intervalo de confiança a 95\%.

Nota: o total da soma dos participantes apresenta pequenas variações devido a perdas.

* Escore total correspondente às dez perguntas do Protocolo de Qualidade de Vida e Voz;

** Escore do domínio físico correspondente às perguntas 1, 2, 3, 6, 7 e 9 do Protocolo de Qualidade de Vida e Voz;

*** Escore do componente sócio-emocional correspondente às perguntas 4, 5, 8 e 10 do Protocolo de Qualidade de Vida e Voz.

\section{Discussão}

O presente estudo mostrou que a percepção da qualidade de vida relacionada à voz foi relativamente boa entre as professoras estudadas, e que tanto as variáveis da organização do trabalho quanto da saúde vocal e mental estão associadas a uma pior qualidade de vida relacionada à voz. Cansaço vocal, piora na qualidade da voz, afastamento da carreira por causa da voz e relacionamento ruim com alunos foram positivamente associados com a pior qualidade de vida relacio- nada à voz nos domínios físico e sócio-emocional. A menor possibilidade de criatividade no trabalho foi relevante tanto para a qualidade de vida relacionada à voz físico quanto sócio-emocional, enquanto a menor margem de autonomia no trabalho e a presença de transtorno mental relacionaram-se à pior qualidade de vida em relação à voz apenas no domínio sócio-emocional.

Este inquérito utilizou um bom tamanho de amostra, além de aleatoriedade em sua seleção, para garantir a validade interna dos resultados encontrados. O estudo transversal tem como 
Associações entre a pior qualidade de vida relacionada à voz e as variáveis que permaneceram independentemente associadas no modelo final, na análise multivariada.

\begin{tabular}{|c|c|c|}
\hline \multicolumn{3}{|c|}{ Pior qualidade de vida relacionada à voz total } \\
\hline Variáveis independentemente associadas & RP & IC95\% \\
\hline \multicolumn{3}{|l|}{ Relato de cansaço vocal } \\
\hline Não & 1,00 & \\
\hline Às vezes & 2,62 & $1,85-3,70$ \\
\hline Diariamente & 3,84 & $2,62-5,62$ \\
\hline \multicolumn{3}{|l|}{ Relato de piora na qualidade da voz } \\
\hline Não & 1,00 & \\
\hline Às vezes & 2,63 & $1,93-3,59$ \\
\hline Diariamente & 4,4 & $3,13-6,19$ \\
\hline \multicolumn{3}{|l|}{ Afastamento da carreira por causa da voz } \\
\hline Nunca & 1,00 & \\
\hline Há mais de 6 meses & 1,29 & $1,12-1,48$ \\
\hline Nos últimos 6 meses & 1,49 & $1,16-1,91$ \\
\hline \multicolumn{3}{|l|}{ Consumo de água durante as aulas } \\
\hline Não & - & - \\
\hline Sim & - & - \\
\hline \multicolumn{3}{|l|}{ Margem de autonomia no trabalho } \\
\hline Grande & 1,00 & \\
\hline Razoável/Pequena & 1,21 & $1,00-1,46$ \\
\hline \multicolumn{3}{|l|}{ Possibilidade de ser criativo } \\
\hline Grande & 1,00 & \\
\hline Razoável/Pequena & 1,22 & $1,05-1,42$ \\
\hline \multicolumn{3}{|l|}{ Ruído na sala de aula } \\
\hline Desprezível ou razoável & 1,00 & \\
\hline Elevado ou insuportável & 1,26 & $1,08-1,47$ \\
\hline \multicolumn{3}{|l|}{ Relacionamento com alunos } \\
\hline Bom & 1,00 & \\
\hline Razoável & 1,13 & $0,95-1,34$ \\
\hline Ruim & 1,42 & $1,06-1,89$ \\
\hline \multicolumn{3}{|l|}{ Transtorno mental } \\
\hline GHQ - & - & - \\
\hline $\mathrm{GHO}+$ & - & - \\
\hline
\end{tabular}

Pior qualidade de vida relacionada à voz física **

Variáveis independentemente associadas

\begin{tabular}{|c|c|c|}
\hline \multicolumn{3}{|l|}{ Relato de cansaço vocal } \\
\hline Não & 1,00 & \\
\hline Às vezes & 2,66 & $1,83-3,86$ \\
\hline Diariamente & 4,00 & $2,66-6,04$ \\
\hline \multicolumn{3}{|c|}{ Relato de piora na qualidade da voz } \\
\hline Não & 1,00 & \\
\hline Às vezes & 2,75 & $1,97-3,84$ \\
\hline Diariamente & 4,23 & $2,92-6,13$ \\
\hline \multicolumn{3}{|c|}{ Afastamento da carreira por causa da voz } \\
\hline Nunca & 1,00 & \\
\hline Há mais de 6 meses & 1,34 & $1,16-1,54$ \\
\hline Nos últimos 6 meses & 1,63 & $1,25-2,11$ \\
\hline \multicolumn{3}{|c|}{ Consumo de água durante as aulas } \\
\hline Não & 1,00 & \\
\hline Sim & 0,84 & $0,71-0,99$ \\
\hline
\end{tabular}

(continua) 


\begin{tabular}{|c|c|c|}
\hline \multicolumn{3}{|c|}{ Pior qualidade de vida relacionada à voz física ** } \\
\hline Variáveis independentemente associadas & RP & IC95\% \\
\hline \multicolumn{3}{|l|}{ Margem de autonomia no trabalho } \\
\hline Grande & - & - \\
\hline Razoável/Pequena & - & - \\
\hline \multicolumn{3}{|l|}{ Possibilidade de ser criativo } \\
\hline Grande & 1,00 & \\
\hline Razoável/Pequena & 1,20 & $1,04-1,39$ \\
\hline \multicolumn{3}{|l|}{ Ruído na sala de aula } \\
\hline Desprezivel ou razoável & 1,00 & \\
\hline Elevado ou insuportável & 1,35 & $1,15-1,58$ \\
\hline \multicolumn{3}{|l|}{ Relacionamento com alunos } \\
\hline Bom & 1,00 & \\
\hline Razoável & 1,08 & $0,89-1,31$ \\
\hline Ruim & 1,53 & $1,18-1,98$ \\
\hline \multicolumn{3}{|l|}{ Transtorno mental } \\
\hline $\mathrm{GHO}-$ & - & - \\
\hline $\mathrm{GHO}+$ & - & - \\
\hline \multicolumn{3}{|c|}{ Pior qualidade de vida relacionada à voz sócio-emocional *** } \\
\hline Variáveis independentemente associadas & $\mathrm{RP}$ & IC95\% \\
\hline \multicolumn{3}{|l|}{ Relato de cansaço vocal } \\
\hline Não & 1,00 & \\
\hline Às vezes & 1,87 & $1,43-2,45$ \\
\hline Diariamente & 2,55 & $1,89-3,44$ \\
\hline \multicolumn{3}{|l|}{ Relato de piora na qualidade da voz } \\
\hline Não & 1,00 & \\
\hline Às vezes & 2,33 & $1,80-3,01$ \\
\hline Diariamente & 3,29 & $2,47-4,40$ \\
\hline \multicolumn{3}{|l|}{ Afastamento da carreira por causa da voz } \\
\hline Nunca & 1,00 & \\
\hline Há mais de 6 meses & 1,26 & $1,11-1,43$ \\
\hline Nos últimos 6 meses & 1,35 & $1,00-1,82$ \\
\hline \multicolumn{3}{|l|}{ Consumo de água durante as aulas } \\
\hline Não & - & - \\
\hline Sim & - & - \\
\hline \multicolumn{3}{|l|}{ Margem de autonomia no trabalho } \\
\hline Grande & 1,00 & \\
\hline Razoável/Pequena & 1,34 & $1,12-1,60$ \\
\hline \multicolumn{3}{|l|}{ Possibilidade de ser criativo } \\
\hline Grande & 1,00 & \\
\hline Razoável/Pequena & 1,19 & $1,04-1,37$ \\
\hline \multicolumn{3}{|l|}{ Ruído na sala de aula } \\
\hline Desprezível ou razoável & - & - \\
\hline Elevado ou insuportável & - & - \\
\hline \multicolumn{3}{|l|}{ Relacionamento com alunos } \\
\hline Bom & 1,00 & \\
\hline Razoável & 1,26 & $1,07-1,47$ \\
\hline Ruim & 1,48 & $1,13-1,94$ \\
\hline \multicolumn{3}{|l|}{ Transtorno mental } \\
\hline GHO - & 1,00 & \\
\hline $\mathrm{GHO}+$ & 1,16 & $1,01-1,33$ \\
\hline
\end{tabular}

RP: razão de prevalência; IC95\%: intervalo de confiança a 95\%; GHQ: General Health Questionnaire.

Nota: o total da soma dos participantes apresenta pequenas variações devido a perdas.

* Escore total correspondente às dez perguntas do Protocolo de Qualidade de Vida e Voz;

** Escore do domínio físico correspondente às perguntas 1, 2, 3, 6, 7 e 9 do Protocolo de Qualidade de Vida e Voz;

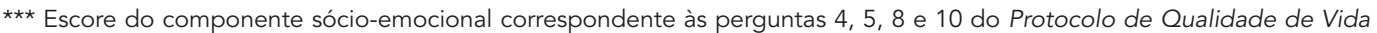
e Voz. 
principais vantagens a rapidez, o baixo custo e a possibilidade de, a partir de amostragem representativa de uma população, descrever características da mesma e ainda explorar possíveis associações entre as variáveis dependentes e independentes. Este estudo teve caráter exploratório, não tendo por objetivo estabelecer causalidade. É importante enfatizar, entretanto, que a qualidade de vida relacionada à voz é uma condição dinâmica e, portanto, os mesmos fatores podem influenciar e ser influenciados pela percepção da qualidade de vida. Outro aspecto que necessita ser salientado é o viés de memória, visto que, pessoas que têm ou tiveram algum problema vocal podem lembrar mais de determinados fatores do que as sem histórico de disfonia, mostrando-se mais sensíveis, por exemplo, à percepção do ruído.

Os escores do QVV encontrados neste estudo estiveram abaixo dos valores obtidos para pessoas sem problemas vocais no estudo de validação do V-RQOL (total = 98,0, sócio-emocional $=98,8$ e físico $=97,3) 20$ e em pesquisa sobre o grau de relação entre qualidade vocal e medidas de qualidade de vida (total $=$ sócio-emocional $=$ físico $=100,0)$ 22. Indivíduos com disfonia neurológica por lesão de massa ou inflamatória tiveram escores mais baixos do que os encontrados no presente estudo (total $=53,5$, físico $=51,9$ e sócioemocional $=55,9) 20$.

Sujeitos com problemas vocais orgânicos crônicos tiveram média de escores bem menor do que a encontrada nas professoras estudadas. Pacientes com disfonia espasmódica adutora tiveram escores total $=30,6$ e 32,7; físico = 28,9 e 30,5 e sócio-emocional $=33,1$ e 36,0 23,24. Laringectomizados apresentaram os seguintes escores: total $=65,8$, físico $=59,9$ e sócio-emocional $=74,625$. A média do escore total do QVV encontrada em pesquisa com 120 professores do ensino fundamental de escolas públicas de Ribeirão Preto, São Paulo, foi idêntica à encontrada no presente estudo 26.

Apesar da elevada prevalência de cansaço vocal e de piora na qualidade da voz, encontrada, os escores do QVV não refletiram a influência esperada destes sintomas na qualidade de vida relacionada à vida das professoras pesquisadas. É necessário salientar que o QVV foi construído para auxiliar na quantificação da influência da disfonia no dia-a-dia do indivíduo e tem sido muito utilizado no acompanhamento da evolução do tratamento de pacientes 23,24,25,27,28,29.

Também é importante lembrar que no presente estudo as professoras provavelmente não possuíam graves problemas de voz, por estarem trabalhando. Ademais, o impacto do problema vocal na qualidade de vida do indivíduo não é di- retamente proporcional à disfonia $30 \mathrm{e}$, algumas vezes, a rouquidão e outros sintomas podem ser encarados pelo professor como inerentes à profissão. Portanto, mesmo que o professor tenha problemas no trabalho por causa da voz ( $17 \%$ das professoras referiram ter um problema moderado no trabalho, ocorrendo às vezes ou freqüentemente, por causa da voz - questão 7 do QVV), a sua repercussão na qualidade de vida relacionada à voz parece não ter grande impacto.

Outro aspecto relacionado à qualidade de vida, diz respeito à tendência das pessoas em se manterem com certo nível de bem-estar, apesar das mudanças em seu ambiente 31 . Somente quando essas mudanças excedem um determinado limiar, os fatores ambientais parecem afetar o estado de bem-estar do indivíduo ${ }^{32}$. Apoiando essa hipótese de homeostase, estudo transversal realizado em 1.457 pacientes com diferentes problemas crônicos de saúde e 1.851 indivíduos saudáveis, mostrou que a maior parte dos grupos de pacientes não se diferenciava dos indivíduos saudáveis em relação aos escores psicológico, físico, social e total da qualidade de vida 13 .

O domínio físico da qualidade de vida relacionada à voz, neste e em outros estudos 22,23,24,25, foi o que apresentou menor escore médio. Os incômodos físicos provocados por problemas vocais, tais como sensação de cansaço para falar, dificuldade para falar forte em ambiente ruidoso e precisar respirar muitas vezes enquanto fala, parecem assumir um papel mais importante na percepção da qualidade de vida relacionada à voz do que fatores relacionados ao componente sócio-emocional. Estudo de Arnold et al. 13, sobre QV realizado em pacientes com diferentes doenças crônicas, utilizando o MOS (SF-20) - Short-Form General Health Survey (Stewart et al., 1988, apud Arnold et al. 13), demonstrou que a maior parte das doenças afetam mais o domínio físico do que o psicológico. Parece existir uma hierarquia no impacto de cada domínio na qualidade de vida, sendo que, na maioria das doenças o funcionamento físico afeta o psicológico e este o social. Essa hierarquia pode variar entre as diversas enfermidades. Problemas como os dermatológicos, que comprometem a aparência física, tendem a afetar primeiramente o funcionamento social 13 .

O relato de sintomas vocais, fortemente associado à qualidade de vida no presente estudo, está intrinsecamente relacionado à presença de alterações laríngeas e, pessoas com queixa vocal grave, que continuam trabalhando, podem desenvolver problemas crônicos. Três estudos utilizando questionários semelhantes para pesquisa de sintomas vocais mostraram que sujeitos que relataram dois sintomas ocorrendo ao 
menos uma vez por semana tinham disfonia orgânica 15,16,33.

Afastamento do trabalho por problemas na voz esteve associado à pior qualidade de vida relacionada à voz total e em ambos os domínios, mostrando um gradiente de risco. As professoras afastadas nos últimos seis meses apresentaram até quatro vezes mais chances de ter pior qualidade de vida relacionada à voz. Embora essa variável não expresse o tempo de afastamento, sugere a cronicidade da disfonia e o conseqüente absenteísmo na população estudada. O afastamento da sala de aula geralmente ocorre quando o professor procura por atendimento médico devido a alguma queixa vocal e, apesar de aproximadamente $12 \%$ das professoras terem referido sintomas vocais diários, nas duas últimas semanas, somente $7 \%$ procuraram médico ou fonoaudiólogo por causa de problemas na voz no mesmo período e, apenas $1,4 \%$ das professoras foi afastada do trabalho no último mês. Estudos têm demonstrado que apesar da grande prevalência desses sintomas, poucos professores buscam atendimento especializado 3,34 e apenas $17 \%$ a $20 \%$ dos professores são afastados da sala de aula 2,5 .

A ingestão de água durante as aulas foi referida por $71 \%$ das professoras e permaneceu independentemente associada à pior qualidade de vida relacionada à voz no domínio físico. As professoras que não bebiam água durante as aulas tiveram até $50 \%$ menos chances de terem pior qualidade de vida relacionada à voz no domínio físico do que as que bebiam. Diversos estudos abordam a importância da água na manutenção e melhora da qualidade vocal $35,36,37,38$, porém os resultados encontrados parecem contradizer estas afirmações. É necessário lembrar que este estudo é transversal, portanto as variáveis dependentes e independentes foram coletadas simultaneamente, dificultando o estabelecimento de precedência da exposição sobre seu possível efeito. Sob esse pressuposto, acredita-se que, provavelmente, as pessoas que têm pior qualidade de vida relacionada à voz convivem com problemas vocais e bebem mais água como conseqüência da disfonia, por recomendação de especialistas e de colegas, ou por sentir mais necessidade, para aliviar os sintomas das alterações vocais, como o esforço para falar. Ainda em relação ao hábito de beber água, este deve ser um efeito positivo do Programa de Saúde Vocal da Prefeitura Municipal de Belo Horizonte.

Ruído elevado/insuportável na sala de aula esteve independentemente associado à pior qualidade de vida relacionada à voz total e no domínio físico. O nível considerado adequado para a aprendizagem é de uma relação entre si- nal/ruído acima de $+15 \mathrm{~dB}$ e, em estudo realizado numa escola de ensino fundamental, na cidade de São Paulo, os níveis de ruídos variaram entre 58 e $84 \mathrm{~dB}(\mathrm{~A})$, chegando a $110 \mathrm{~dB}$ (A) durante o intervalo, sendo que, a intensidade da voz dos professores variou de 79.5 a $90.5 \mathrm{~dB}$ (A), valores encontrados somente na voz gritada, denotando grande desgaste vocal 39 . Dados semelhantes foram encontrados analisando a intensidade da voz de doze professoras em relação ao ruído em uma escola da rede estadual da cidade de Jacareí, no Estado de São Paulo 40. A intensidade vocal variou de 70 a $94 \mathrm{~dB}$ e o ruído ambiental de 52 a 84dBA. A maioria dos professores pesquisados no ensino particular em Vitória da Conquista, Bahia, relatou fazer força para ser ouvido ${ }^{41}$. Simberg et al. 16 também mostraram associação entre ruído e relato de sintomas vocais, sendo que $54 \%$ dos professores pesquisados referiram sofrer perturbação semanalmente. Em estudo com 228 docentes de uma instituição de ensino superior, $46 \%$ dos professores queixaram-se de presença de ruído elevado no ambiente laboral 42 . O ruído ambiental associado ao uso prolongado da voz é um dos importantes fatores determinantes de uma carga vocal intensa 43,44 .

Aspectos da organização do trabalho mantiveram associação independente com a pior qualidade de vida relacionada à voz nos domínios físico e sócio-emocional. Criatividade esteve associada ao componente físico e ao domínio socioemocional, e margem de autonomia foi relevante apenas no domínio sócio-emocional. Esses resultados evocam o modelo "demandacontrole" de Karasek, que define quatro grandes grupos de ocupações em função dos níveis de demandas psicológicas e controle sobre o trabalho, predizendo que o trabalho em alta exigência, maior demanda e menor controle, concentra os maiores riscos à saúde dos trabalhadores 45 .

Relacionamento ruim com alunos também esteve associado à pior qualidade de vida relacionada à voz total e em ambos os domínios. As dificuldades de relacionamento com os alunos podem levar a uma grande solicitação vocal. Simberg et al. 16 demonstraram associação entre indisciplina dos alunos e relato de sintomas vocais. Silvany Neto et al. 46 encontraram associação entre queixa de nódulos vocais e relato de desgaste na relação professor-aluno. Estudo recente sobre ambiente e carga de trabalho 47 mostrou que indisciplina e ruído causam exaustão em professores, assim como o desrespeito dos alunos e classes ruidosas também contribuem para reação de estresse em professores.

A indisciplina, o grande número de alunos nas salas de aula e o perfil do educando poderiam explicar o relacionamento ruim entre pro- 
fessores e alunos. Estudo qualitativo do trabalho de nove professoras de uma escola pública no norte de Minas Gerais identificou a indisciplina dos alunos como a principal dificuldade enfrentada pelo profissional. A tarefa das professoras foi descrita como ensinar coletivamente e acompanhar individualmente o processo de cada aluno. A autora sinalizou a presença de uma média de 34 alunos na sala como fator de constrangimento, uma vez que o atendimento individual acaba favorecendo a indisciplina dos alunos. Ademais, a autora sugere que a mudança do perfil do aluno oriundo de um ambiente social e familiar cada vez mais precário impõe novas tarefas aos professores, para as quais eles, muitas vezes, estão mal preparados 48 .

As condições de trabalho que estavam associadas estatisticamente à queixa de nódulos nas pregas vocais em 573 professores de 60 escolas da rede particular de ensino de Salvador, Bahia, foram: ambiente estressante e intranqüilo, desgaste na relação professor-aluno, salas inadequadas, trabalho repetitivo, desempenho das atividades sem materiais e equipamentos adequados e exposição ao pó de giz 46 .

$\mathrm{O}$ estresse de forma geral associado ao trabalho é um dos fatores que contribuem para a prevalência de problemas vocais nos professores 16,49,50. A elevada prevalência de transtorno mental nas professoras estudadas e sua associação independente com a pior qualidade de vida relacionada à voz no domínio sócio-emocional revelam as condições precárias de trabalho e indicam uma importante relação entre estresse, emoção e voz. Neste estudo, transtorno mental foi definido como transtorno somatoforme de ansiedade e de depressão, não-psicótico, que evidencia problemas caracterizados pelos sintomas: fadiga, irritabilidade ou nervosismo, esquecimento, dificuldade de concentração, alterações do sono e queixas somáticas 18 .

Este estudo avaliou somente os aspectos da qualidade de vida relacionados à voz, em professoras que estavam trabalhando. Portanto, analisando rapidamente os valores médios nos escores total e nos domínios físico e sócio-emocional do QVV, podemos inferir, erroneamente, que a influência da voz parece não ser muito significativa no dia-a-dia dos professores. Porém, os resultados encontrados mostraram associações importantes referentes à pior qualidade de vida relacionada à voz, principalmente no domínio físico, e a média do escore do componente físico $(59,9)$ apresentada por laringectomizados 25 é próxima do menor quartil do escore físico do QVV $\left(\mathrm{P}_{25}=67\right)$ encontrado no presente estudo.

Além disso, a qualidade de vida é uma condição multidimensional e, somente nas doenças crônicas, como problemas pulmonares e enxaqueca, que afetam todos os componentes da qualidade de vida (físico, psicológico e social), é que os domínios da qualidade de vida relacionada à saúde contribuem para explicar a maior parte da variabilidade da qualidade de vida geral 13 .

Os resultados do presente estudo indicam a necessidade de se investigar melhor o papel das condições de trabalho, incluindo os fatores do ambiente psicossocial, em especial as dificuldades de relacionamento com alunos, na qualidade de vida relacionada à voz. Pesquisas futuras deveriam buscar compreender melhor os elementos que compõem essa complexa realidade, de forma a contribuir para políticas de intervenção efetivas no ambiente de trabalho, que envolvam trabalhadores e gestores da educação.

\section{Conclusão}

As associações encontradas entre a pior percepção da qualidade de vida relacionada à voz e os aspectos comportamentais e de saúde das professoras, do ambiente e da organização do trabalho e de relacionamento com alunos, mostram a necessidade de deslocar as atuais ações preventivas focalizadas no plano individual para o plano das condições ambientais relacionadas ao desenvolvimento do trabalho docente. 


\section{Resumo}

A disfonia limita o trabalho docente e compromete a qualidade de vida do professor. O presente trabalho investigou fatores associados à pior qualidade de vida relacionada à voz em 2.133 professoras da rede municipal de ensino fundamental de Belo Horizonte, Minas Gerais, Brasil. A qualidade de vida foi mensurada pelo Protocolo de Qualidade de Vida e Voz, um questionário internacional padronizado com dois domínios: sócio-emocional e físico. As professoras foram agrupadas segundo o escore final dos dominios, sendo o menor quartil definido como ponto de corte para uma pior qualidade de vida relacionada à voz. Menor criatividade no trabalho e relacionamento ruim com alunos estiveram associados com a pior qualidade de vida relacionada à voz em ambos os domínios. Transtorno mental $\left(G H Q_{12} \geq 4\right)$ esteve associado somente ao domínio sócio-emocional, e ruído na sala de aula apenas ao componente físico. Os resultados indicam que a qualidade de vida é uma dimensão fundamental para analisar a disfonia no trabalho docente e que condições ruins de trabalho estão associadas a uma pior qualidade de vida relacionada à voz.

Disfonia; Docentes; Qualidade de Vida; Saúde Ocupacional

\section{Referências}

1. Jardim R. Voz, trabalho docente e qualidade de vida [Dissertação de Mestrado]. Belo Horizonte: Faculdade de Medicina, Universidade Federal de Minas Gerais; 2006.

2. Smith E, Gray SD, Dove H, Kirchner L, Heras H. Frequency and effects of teachers voice problems. JVoice 1997; 11:81-7.

3. Russell A, Oates J, Greenwood KM. Prevalence of voice problems in teachers. J Voice 1998; 12:46779.

4. Melnyk P, Jamardo B, Cacace M, Pardo $\mathrm{H}$, Pino AA, Tomasetti A, Cortizas MMA, Hurtado DE, Braier MR, Verretilne G. Considerations about teachers'dysphonias. Int Congr Ser 2003; 1240:1293-6.

5. Roy N, Merril RM, Thibeault S, Gray SD, Smith EM. Voice disorders in teachers and the general population: effects on work performance, attendance, and future career choices. J Speech Lang Hear Res 2004; 47:542-51.

6. Krischke S, Weigelt S, Ulrich H, Köllner V, Klotz M, Eysholdt $\mathrm{U}$, et al. Quality of life in dysphonic patients. J Voice 2005; 19:132-7.

\section{Colaboradores}

R. Jardim contribuiu no levantamento dos dados por meio do trabalho de campo, análise do banco de dados, levantamento bibliográfico e redação. S. M. Barreto colaborou na orientação sobre a condução do trabalho de campo e análise dos dados, redação e revisão do texto. A. A. Assunção participou na orientação sobre a condução do trabalho de campo e redação do texto.
7. Yiura LH, Miranda SM, Margall SAC. Comparação da produção gráfica de crianças a partir da emissão vocal de professores com e sem alterações de voz. In: Sociedade Brasileira de Fonoaudiologia, organizador. Atualização em voz, linguagem, audição e motricidade oral. São Paulo: Frôntis Editorial 1999. p. 95-110. (Coleção Sociedade Brasileira de Fonoaudiologia).

8. Rogerson J, Dodd B. Is there an effect of dysphonic teachers' voices on children's processing of spoken language? J Voice 2005; 19:47-60.

9. Gonçalves GBB. Uso profissional da voz em sala de aula e organização do trabalho docente [Dissertação de Mestrado]. Belo Horizonte: Faculdade de Educação, Universidade Federal de Minas Gerais; 2003.

10. Consenso Nacional sobre Voz Profissional. Rev Bras Otorrinolaringol 2004; 70 (6 Suppl).

11. Siqueira MJT, Ferreira ESF. Saúde das professoras das séries iniciais: o que o gênero tem a ver com isso? Psicol Ciênc Prof 2003; 23:76-83. 
12. Gill TM, Feinstein AR. A critical appraisal of the quality of quality-of-life measurements. JAMA 1994; 272:619-26.

13. Arnold R, Ranchor AV, Sanderman R, Kempen GIJM, Ormel J, Suurmeijer TPBM. The relative contribuition of domains of quality of life to overall quality of life for different chronic diseases. Qual Life Res 2004; 13:883-96.

14. Organização Mundial da Saúde. Classificação internacional de funcionalidade, incapacidade e saúde. São Paulo: Edusp; 2003.

15. Sala E, Laine A, Simberg S, Pentti J, Suonpää J. The prevalence of voice disorders among day care center teachers compared with nurses: a questionnaire and clinical study. J Voice 2001; 15:413-23.

16. Simberg S, Sala E, Vehmas K, Laine A. Changes in the prevalence of vocal symptoms among teachers during a twelve-year period. J Voice 2005; 19:95102.

17. Thibeault SL, Merrill RM, Roy N, Gray SD, Smith EM. Occupational risk factors associated with voice disorders among teachers. Ann Epidemiol 2004; 14:786-92.

18. Goldberg DP, Gater R, Sartorius N, Ustun TB, Piccinelli M, Gureje O, et al. The validity of two version of the GHQ in the WHO study of mental illness in general health care. Psychol Med 1997; 27:191-7.

19. Behlau M. Voz: o livro do especialista. Rio de Janeiro: Editora Revinter; 2001.

20. Hogikyan ND, Sethuraman G. Validation of an instrument to measure voice-related quality of life (V-RQOL). J Voice 1999; 13:557-69.

21. Gasparini GGO. Validação do questionário de avaliação de qualidade de vida e voz (QVV) [Dissertação de Mestrado]. São Paulo: Escola Paulista de Medicina, Universidade Federal de São Paulo; 2005.

22. Murry T, Medrado R, Hogikyan ND, Aviv JE. The relationship between ratings of voice quality of life measures. J Voice 2004; 18:183-92.

23. Hogikyan ND, Wodchis WP, Spak C, Kileny PR. Longitudinal effects of botulinum toxin injections on voice-related quality of life (V-RQOL) for patients with adductory spasmodic dysphonia. J Voice 2001; 15:576-86.

24. Rubin AD, Wodchis WP, Spak C, Kileny PR, Hogikyan ND. Longitudinal effects of botox injections on voice-related quality of life (V-RQOL) for patients with adductory spasmodic dysphonia. Part II. Arch Otolayngol Head Neck Surg 2004; 130:415-20.

25. Weinstein GS, El-Sawy MM, Ruiz C, Dooley P, Chalian A, El-Sayed MM, et al. Laryngeal preservation with supracricoid partial laryngectomy results in improved quality of life when compared with total laryngectomy. Laryngoscope 2001; 111:191-9.

26. Grillo MHMM, Penteado RZ. The impact of voice on the quality of life of elementary school teachers. Pró-Fono 2005; 17:321-30.

27. Rontal E, Rontal M. Permanent medialization of the paralyzed vocal fold utilizing botulinum toxin and gelfoam. JVoice 2003; 17:434-41.

28. Boseley ME, Hartnick CJ. assesing the outcome of surgery to correct velophayngeal insufficiency with the pediatric voice outcomes survey. Int J Pediatr Otorhinolaryngol 2004; 68:1429-33.
29. Lindman JP, Gibbons MD, Morlier R, Wiatrak BJ Voice quality or prebubescent children with quiescent recurrent respiratory papillomatosis. Int J Pediatr Otorhinolaryngol 2004; 68:529-36.

30. Ma EP-M, Yiu EM-L. Voice Activity and Participation Profile: Assessing the Impact of Voice Disorders on Daily Activities. J Speech Lang Hear Res 2001; 44:511-24.

31. Cummins RA. The second approximation to na international standard for life satisfaction. Soc Indic Res 1998; 43:307-34.

32. Cummins RA. Objective and subjective quality of life: an interactive model. Soc Indic Res 2000; 52:55-72.

33. Simberg S, Sala E, Rönnema A. Prevalence of voice disorders among future teachers. J Voice 2000; 14:231-5.

34. Smith E, Lemke J, Taylor M, Kirchner L, Hoffman $\mathrm{H}$. Frequency of voice problems among teachers and other occupations. J Voice 1998; 12:480-8.

35. Chan RWK. Does the voice improve with vocal hygiene education? A study of some instrumental voice measures in a group of kindergarten teachers. J Voice 1994; 8:279-91.

36. Pinho SMR. Manual de higiene vocal para profissionais da voz. Carapicuíba: Editora Pró-Fono; 2003.

37. Solomon NP, Glaze LE, Arnold RR, Mersbergen M. Effects of a vocally fatiguing task and systemic hydration on men's voices. J Voice 2003; 17:31-46.

38. Yiu EM, Chan RMM. Effect of hidration and vocal rest on the vocal fatigue in amateur karaoke singers. J Voice 2003; 17:216-27.

39. Martins MIM, Taú MC, Unzueta VMP, MomensohnSantos TM. A interferência do ruído no reconhecimento da fala: análise do ambiente e da voz do professor. In: XX Encontro da Sociedade Brasileira de Acústica e II Simpósio Brasileiro de Metrologia em Acústica e Vibrações. Rio de Janeiro: Sociedade Brasileira de Acústica; 2002. p. 21-4.

40. Pereira MJ, Santos TMM, Viola IC. Influência do ruído em sala de aula sobre a performance vocal do professor. In: Ferreira LP, Costa HO, organizadores. Voz ativa: falando sobre o profissional da voz. São Paulo: Editora Roca; 2000. p. 57-77.

41. Delcor NS, Araújo TM, Reis EJFB, Porto LA, Carvalho FM, Silva MO, et al. Condições de trabalho e saúde dos professores da rede particular de ensino de Vitória da Conquista, Bahia, Brasil. Cad Saúde Pública 2004; 20:187-96.

42. Araújo TM, Paranhos IS. Interface entre trabalho docente e saúde de uma instituição de ensino superior. In: Oliveira DA, organizador. Reformas educacionais na América Latina e os trabalhadores docentes. Belo Horizonte: Autêntica Editora; 2003. p. 103-24.

43. Vilkman E. Ocupational safety and health aspects of voice and speech professions. Folia Phoniatr Logop 2004; 56:220-53.

44. Vilkman E. Voice problems at work: a challenge for occupational safety and health arrangement. Folia Phoniatr Logop 2000; 52:120-5.

45. Araújo TM, Graça CC, Araújo E. Estresse ocupacional e saúde: contribuições do Modelo DemandaControle. Ciênc Saúde Coletiva 2003; 8:991-1003. 
46. Silvany Neto AM, Araújo TM, Alves RL, Azi GR, Dutra FRD, Kavalkievicz C, et al. Condições de trabalho e saúde de professores da rede particular de ensino de Salvador, Bahia. Rev Baiana Saúde Pública 2000; 24:42-56.

47. Simberg S, Sala E, Vehmas K, Laine A. Changes in the prevalence of vocal symptoms among teachers during a twelve-year period. J Voice 2005; 19:95102.
48. Noronha MMB. Condições do exercício profissional da professora e os seus possíveis efeitos sobre a saúde: estudo de casos das professoras do ensino fundamental em uma escola pública de Montes Claros, Minas Gerais [Dissertação de Mestrado]. Belo Horizonte: Universidade Federal de Minas Gerais; 2001.

49. Sapir S, Keidar A, Mather SB. Vocal attrition in teachers: survey findings. Eur J Disord Commun 1993; 28:177-85.

50. Gotaas C, Starr CD. Vocal fatigue among teachers. Folia Phoniatr Logop 1993; 45:120-9.

Recebido em 31/Jul/2006

Versão final reapresentada em 08/Mar/2007

Aprovado em 11/Abr/2007 